\title{
Job Satisfaction in the Health Care Sector: Empirical Evidence from Medical Care in Greece
}

\author{
Alexandra Gkliati, PhD Cand. \\ Harokopio University Athens \\ Dr. Anna Saiti \\ Professor, Harokopio University Athens
}

\begin{abstract}
It is extremely important for employees in every sector of an economy to be satisfied with their work since job satisfaction contributes significantly to improvements in their productiveness and performance. This paper deals with the very sensitive sector of health care in which medical staff provide citizens with health care services. The job satisfaction of these medical care providers is of particular importance when aiming to improve the quality of their services. Literature on job satisfaction among the providers of medical care is limited since researches have focused mainly on users' satisfaction with the medical care services provided. In an era in which many countries worldwide are facing uncertainty and the social insurance systems are confronted with serious problems as they strive to respond to a number of changes, the Greek health care sector is no exception. With particular reference to the Greek reality, due to the heavy recession that the country has been facing for a number of years, health care expenditures have been cut dramatically and, as a result, the working conditions in public hospitals have been negatively influenced. Based on the above, the purpose of this paper is, through empirical investigation, to examine the levels of job satisfaction among Greek doctors who work in public hospitals and to determine the factors that may influence the satisfaction they gain from their work.
\end{abstract}

Keywords: job satisfaction, medical care, doctors, Greece

\section{Introduction and aims of the study}

Employment is a concept inextricably linked with adult's life. In the relevant literature, there is a wide range of work- related topics that aim to the investigation of aspects that can improve working conditions, productivity and the well-being of employees. A typically-related topic is the one of job satisfaction which is extremely important for the productiveness and performance in every occupational sector (Spector, 1997, Brown et al., 1993, Judge et al., 2001). Furthermore, higher levels of job satisfaction can ensure lower absenteeism (Wu et al, 2007), and satisfied employees are more likely to be satisfied with their lives (Lease, 1998). There is also a strong link between job satisfaction and organizational commitment (Alpader, 1990).

It is evident that the last years reflect a period of radical changes as Greece is suffering from severe economic problems and Greek ministers are expected to reduce to a minimum their expenditures. Based on this rule, the Greek health sector has reduced its expenditures while the salaries of doctors have also being subjected to reduction. Apart from the changes, the social security system faces serious problems and there is a general dissatisfaction for the quality of the health services (Moumtzoglou et al., 2000). In the same time, the private expenditures for the health sector have being increased to such an extent that brings Greece to the fist places in Europe, given that the effectiveness of the public health system is not adequate (Tountas et al., 2005). On the other hand, apart from the changes in the structure of health care systems, the financial crisis has an impact on the physical and psychological health of employees. In the years of recession, the job satisfaction levels are questionable and a great challenge for the global community is the avoidance of financial crisis' conversion to a social crisis or to a crisis of healthcare systems.

Based on the above, this study aims to investigate the levels of Greek public sector doctors' job satisfaction and to determine the factors which may influence these levels. 


\section{Job Satisfaction}

Undoubtedly, job satisfaction is a complex concept that has attracted the attention of researchers for several decades now, and many theoretical approaches have been developed for its explanation. In 1911, Frederic Winslow Taylor was the first researcher to introduce the concept and many researchers tried to define its meaning afterwards. However, there is not one universal definition, thus complicating the concept of what job satisfaction is. A wider and predominant definition came from Locke (1974) who defines job satisfaction as 'a pleasurable or positive emotional state resulting from the appraisal of one's job or job experiences' (p.1304). Locke considers professional values as subjective, acquired, and their hierarchy is determined by individuals' assessment based on their significance. Hulin (1991) and Brief (1998) were influenced by Locke's definition and they highlighted the importance of the mental processes, thoughts and feelings.

Another interesting definition is the one of Vroom (1964), who considers satisfaction as a connection between the subjective perception of an employee and the extent to which a person is attracted to the work and manages the achievement of the desired results in his workplace. Alderfer (1972) describes satisfaction as a subjective internal state which is based on the interaction between the individual and the environment and it is synonymous with the fulfillment.

Several theories have been developed for job satisfaction. Content theories highlight that an individual can be satisfied with a job when particular needs or values are attained (Locke, 1974). Herzberg's (1966) two-factor theory indicates that the presence 'motivators' (such as recognition and achievement) leads to job satisfaction while the absence of 'hygienes' (workplace environment, pay) leads to job dissatisfaction. This theory has been criticized due to the fact that it predicts the same levels of job satisfaction for the employees in the same contexts while it seems to ignore the individual differences (Schneider and Locke 1971). On the other hand, the need-based theories focus on the individuals and the level of job satisfaction is defined to the extent of which these needs are fulfilled in a workplace environment (McClelland, 1961). Within this framework, many instruments have been developed in order to measure job satisfaction.

A large amount of research concerning the factors that determine levels job satisfaction has been undertaken. According to Blegen (1993), job satisfaction is a dynamic situation which may vary depending on the personal characteristics, expectations, management or changes in the organisational policy. Several studies such as Bolton (2005) and Wise (2007) revealed the impact of managerial responsibility and style while McNeese Smith (1996) highlighted the importance of management in the organization. Job satisfaction has been playing a crucial role in the management research (Fisher, 2003).

Sutherland and Cooper (1992) suggested that an important factor which contributes to job satisfaction is the social support. A study conducted in United States of America (Eric et al., 2003) showed that the interpersonal relationships between doctors and their colleagues or patients are important contributors to job satisfaction. Another determinant factor for job satisfaction is the wage and the pension systems (Case et al. 2002). To sum up, research suggests that both personal (Kaplow, 1996) and organizational factors (Adams and Parrott, 1994) are linked to job satisfaction.

\section{Job Satisfaction in the medical care sector}

Job satisfaction is a concept that has been studied globally in different workplace contexts and the same applies in the medical care sector as it has received increasing attention in America and Europe in the last decades (Flood \& Fennell, 1995, Davies et al., 2000). Apart from the general positive outcomes of job satisfaction for an organization, these studies revealed that there is a link between doctors' job satisfaction and quality of patient care (Alken et al., 1994, Norrish \& Rundall, 2001). Moreover, doctors' levels of job satisfaction may be of importance to individual career choices (Shanafelt et al., 2002).

In Greece, research for job satisfaction has been conducted mainly in the sectors of education and health (Demoussis and Giannakopoulos, 2007, Koustelios, 2001, Theodossiou and Pouliakas, 2005, Togia et al., 2004) however, doctors are not a sample (professional group) commonly used. Studies suggest that there is a general dissatisfaction from the Greek healthcare system (Moumtzoglou et al., 2000) due to the failure of the public medical care systems to provide adequate health services (Tountas et al., 2005). With particular reference to Greece, literature on job satisfaction among the providers of medical care is limited since researches have focused mainly on users' and nurses satisfaction (e.g. Theodossiou and Pouliakas, 2005, Togia et al., 2004) with the medical care services provided. However, in recent years it appears that some Greek researchers such as Sourmpasi (2006), Papanikolaou (2007), Gerovasiliou (2009), etc., have attempted to analyse this issue as indicated by their Master's thesis and although the sample used by those studies were rather small they have converged to the conclusion that doctors appeared to be satisfied with their jobs. 


\section{Methodology}

\section{1 Participants and procedure}

This cross-sectional study was based on a survey conducted using a sample of doctors coming from 6 Greek hospitals in the metropolitan area of Athens. In total, the sample consisted of 156 doctors (response rate $=94 \%$ ) and included 86 males $(55.1 \%)$ and 70 females $(44.9 \%)$. The mean age of respondents was 38.4 years $(S D=9.1)$ and the mean of the years worked in the specific hospital was 6.88 years $(S D=7)$. A total of $47.4 \%$ of the participants worked in Athens.

Following the official consensus of the hospitals in Athens, the questionnaire was distributed to doctors in person. The questionnaire was accompanied by information related to the aims of the study and their right to withdraw from the research at any stage. In addition, the study's confidentiality and anonymity were emphasized. The participants had one week to complete the questionnaire.

\section{2 Measures}

The questionnaire used in the current research included two different sections. The first section of the questionnaire explored personal and professional characteristics of the respondents, such as age, gender, position and department in the hospital.

Job Satisfaction. The concept of job satisfaction was measured by the sort version of Minnesota Satisfaction Questionnaire developed by Weiss and his colleagues in 1967. This version includes 20 of the 100 original items and each question represents one subscale of the long version. The 20 items are rated on 5-point Likert scale from 1 (very dissatisfied) to 5 (very satisfied). The 20 item responses are averaged to create a total score- the higher the score, the higher the level of job satisfaction. The manual, which examined a wide range of occupational groups, indicates that the median reliability coefficient for intrinsic scale is .86 , for the extrinsic .80 while the reliability of the general satisfaction scale is .90 . That being said, the norms of the questionnaire have been calculated for several groups but doctors are not included. Therefore, a factor analysis for doctors' job satisfaction has been selected for the analysis.

\section{3 Data analysis}

The analysis of the results was performed using the Statistical Package for Social Sciences 23 . The aim of the study was the exploration of the levels of job satisfaction and the determination of the factors that may influence it. Therefore, the mean of job satisfaction's questionnaire has been calculated and a factor analysis has been conducted.

\section{Results}

First, the mean of job satisfaction's questionnaire has been calculated in order to identify the levels of doctors' job satisfaction. The mean was $3.46(S D=0.51)$ and this result demonstrates that doctors are satisfied with their jobs in public hospitals.

The application of factor analysis resulted in the extraction of 4 factors that have an Eigenvalue above 1. Of these, four factors were selected (see Table 1 ) which account for $69.8 \%$ of the total sample. The Cronbach's alpha reliability coefficient was 0.88 . Based on the empirical findings, the following factors were extracted:

The first factor was intrinsic motives including creativity, initiatives. These were: The chance to work alone on the job, The chance to do different things from time to time, The chance to be "somebody" in the community, The way my job provides for steady employment, The chance to do things for other people, The chance to tell people what to do, The chance to do something that makes use of my abilities, The way company policies are put into practice, The freedom to use my own judgment, The chance to try my own methods of doing the job, The praise I get for doing a good job, The feeling of accomplishment I get from the job.

The second factor covered considerations relevant to task enrichment and work climate. These were: Being able to keep busy all the time, being able to do things that don't go against my conscience, The working conditions, The way my coworkers get along with each other.

The third factor was supervision and leadership. This covered: The way my boss handles his/her workers, The competence of my supervisor in making decisions. 
The fourth factor was extrinsic motives. This covered: The way company policies are put into practice, My pay and the amount of work I do, The chances for advancement on this job.

Table 1: Variables included in each factor and factor Loadings

\begin{tabular}{|c|c|c|}
\hline Factors & Variables & Loadings \\
\hline \multirow{11}{*}{$\begin{array}{l}\text { Factor } 1 \\
\text { Intrinsic motives including creativity, initiatives }\end{array}$} & The chance to work alone on the job & 0.875 \\
\hline & the chance to do different things from time to time & 0.821 \\
\hline & The chance to be "somebody" in the community & 0.876 \\
\hline & The way my job provides for steady employment & 0.731 \\
\hline & The chance to do things for other people & 0.700 \\
\hline & The chance to tell people what to do & 0.877 \\
\hline & $\begin{array}{l}\text { The chance to do something that makes use of my } \\
\text { abilities }\end{array}$ & 0.857 \\
\hline & The freedom to use my own judgment & 0.857 \\
\hline & The chance to try my own methods of doing the job & 0.890 \\
\hline & The praise I get for doing a good job & 0.849 \\
\hline & The feeling of accomplishment I get from the job & 0.861 \\
\hline \multirow{4}{*}{$\begin{array}{l}\text { Factor } 2 \\
\text { Task enrichment and work climate }\end{array}$} & Being able to keep busy all the time & 0.631 \\
\hline & $\begin{array}{l}\text { being able to do things that don't go against my } \\
\text { conscience }\end{array}$ & 0.488 \\
\hline & The working conditions & 0.791 \\
\hline & The way my co-workers get along with each other. & 0.523 \\
\hline \multirow{2}{*}{$\begin{array}{l}\text { Factor } 3 \\
\text { Supervision and leadership }\end{array}$} & The way my boss handles his/her workers & 0.853 \\
\hline & The competence of my supervisor in making decisions & 0.808 \\
\hline \multirow{3}{*}{$\begin{array}{l}\text { Factor } 4 \\
\text { Extrinsic motives }\end{array}$} & The way company policies are put into practice & 0.453 \\
\hline & My pay and the amount of work I do & 0.845 \\
\hline & The chances for advancement on this job. & 0.627 \\
\hline
\end{tabular}

\section{Discussion}

This study was designed to investigate the levels of job satisfaction among doctors of Greek public hospitals. The findings of the present study revealed that doctors appeared to be satisfied with their jobs. These findings are in accordance with the relevant Greek studies (Sourmpasi, 2006, Papanikolaou, 2007, Gerovasiliou, 2009) regarding job satisfaction in the medical care sector (doctors).

The factor analysis revealed the four factors which contribute to the degree of job satisfaction for doctors. According to the empirical results, these factors are: the intrinsic motives including creativity and initiatives, the task enrichment and work 
climate, the supervision and leadership while the fourth factor related to the extrinsic motives (such as pay). A significant difficulty in assessing job satisfaction is that people might be satisfied with some aspects of their jobs while being dissatisfied with others (Spagnoli et al., 2012) and this is the reason why multidimensional measures of job satisfaction have been developed and they have been adapted as the main way of measurement from the occupational psychology (Hirschfeld, 2000).

Previous research on factor structure of Minnesota Satisfaction Questionnaire states different results. For example, Moorman (1993, in Fields, 2002) found two factors; the intrinsic and extrinsic satisfaction while Schriesheim and his colleagues (1993) suggested that there is also the factor of general satisfaction. On the other hand, Mathieu (1991) yielded four factors. These factors are: intrinsic satisfaction, extrinsic satisfaction, recognition and authority/social utility. A recent study (Martins, 2012) in Portugal suggests that Minnesota Satisfaction questionnaire is a valid instrument for measuring the job satisfaction of global hospital workers.

Intrinsic motives, which is the most important factor of our analysis, includes eleven questions for creativity, initiatives and work autonomy. Research on job satisfaction suggests that creativity can affect job satisfaction (Shalley et al., 2000). Finn (2001) highlighted the work autonomy as one of the most important component of nurses' job satisfaction. Hence, this analysis revealed that Greek doctors pay most attention to their sense of freedom in their work and to their sense of offering to other people.

With regard to the second factor, namely, task enrichment and work climate, this can also be confirmed by the literature which states that enrichment is a very important job characteristic and a predictor for job satisfaction (O'Reilly and Caldwell, 1979). Work climate in various occupational contexts has also been considered as a factor that can affect the levels of job satisfaction (Babin and Boles, 1996). Regarding the factor of the supervision and leadership, there is a great amount of research (Hurlbert, 1991) that confirms their contribution to the development of job satisfaction and it also suggests that it can provide lessons for management (Kim, 2002).

The final factor revealed by the empirical results was the extrinsic motives which include pay, policies and chances for advancement. Malka and Chatman (2003), found a positive correlation between the pay and the satisfaction levels while the policies of the organization have been extensively studied as a part of the organization's culture (Trice and Beyer, 1993). The latter might be able to explain the reason why Greek doctors are satisfied with their jobs, even if the recession has affected their salaries and hospitals' policies, employees still be satisfied since the most important factor appeared to be the intrinsic motives instead of the extrinsic.

The main limitation of the present study is its cross-sectional design which cannot provide evidence for casual references or relationships and the fact that this study was based on self-report measures. Furthermore, the sample of the research was relatively small and it was derived from only six hospitals of the Greek public healthcare system. Nevertheless, the sample cannot be characterized as homogenous due to the fact that participants were working in different departments in the hospital, so they deal with different tasks. Regarding the period when the study was conducted is one of many changes occur in the public hospitals due to the fact that some hospitals have new managers while other hospitals expect the allocation of new managers.

\section{Conclusion}

Future research could include a wider sample of doctors from Greek hospitals both from the capital, Athens, and from the province so as to confirm the factors which contribute to doctors' satisfaction. Another suggestion for future research is external validity's verification of factor structure. Moreover, a questionnaire with more than twenty questions can provide enhanced factor loadings that may reveal more factors contributing to job satisfaction.

The current study has shown that doctors of the public hospitals in Greece are satisfied with their jobs. Furthermore, the most important factor for employee's satisfaction appears to be the intrinsic motives. These results suggests that even in the years of recession, employees in the public contexts can be satisfied with their jobs as the work autonomy, the chance of multi-tasks and the sense of the accomplishment are considered as more important for their satisfaction.

\section{References}

[1] Adams, R.J., \& Parrott R. (1994). Pediatric nurses' communication of role expectations to parents of hospitalized children. Journal of Applied Communications Research, 22(1), 36-47. 
[2] Alderfer, C.P. (1972). Human need in organizational settings. The Free Press of Glendoc. New York.

[3] Alken, L. H., Smith, H.L., \& Lake, E.T (1994). Lower Medicare mortality among a set of hospitals known for good nursing care. Med care, 32, 771-787.

[4] Alpander, G.G. (1990). Relationship between commitment to hospital goals and job satisfaction: a case study of a nursing department. Health Care Management Review 15(4), 51-62

[5] Babin, B.J., \& Boles, J.S. (1996) .The effects of perceived co-worker involvement and supervisor support on service provider role stress, performance, and job satisfaction. Journal of Retailing, 72(1), 57-75.

[6] Blegen, M.A. (1993). Nurses job-satisfaction- A metaanalysis of related variables. Nursing Research, 42(1), 3641.

[7] Bolton, S. (2005). Making up managers: the case of NHS nurses. Work Employment and Society 19(1), 5-23.

[8] Brief, A.P. (1998). Attitudes in and around organisations. California: Sage Publications.

[9] Brown, S.P., Cron, W.L., \& Leigh, T.W. (1993). Do feelings of success mediate sales performance-work attitude relationships? Journal of the Academy of Marketing Science, 21, 91-99.

[10] Case, B., Himmelstein, D. Woolhandler, S. (2002). No Care for the Caregivers: Declining Health Insurance Coverage for Health Care Personnel and Their Children. American Journal of Public Health, 92,404-408.

[11] Davies, H.T, Nutley, S.M, Mannion, R. (2000). Organisational culture and quality of healthcare. Quality healthcare, 9, 111-119.

[12] Demoussis, M., \& Giannakopoulos, N. (2007). Exploring Job satisfaction in private and public employment: Empirical evidence from Greece. Labour, 21(2), 333-359.

[13] Eric, S.W, Linzer, M., Pathman, E.D. (2003). What do physicians want in their ideal job? Journal of Medical Practice Management, 179-183.

[14] Fields, D.L. (2002). Taking the Measure of Work: A Guide to Validated Scales for Organizational Research and Diagnosis. Thousand Oaks, CA: Sage.

[15] Finn, C.P. (2001). Autonomy: an important component for nurses' job satisfaction. International Journal of Nursing Studies 38, 349-357.

[16] Fisher, C.D. (2003). Why Do Lay People Believe That Satisfaction and Performance Are Correlated? Possible Sources of a Commonsense Theory. Journal of Organizational Behavior, 24(6), 753-77.

[17] Flood, A.B, Fennell, M.L. (1995). Through the lenses of organizational sociology: the role of organization theory and research in conceptualizing and examining our health care system. Journal of Health and Social Behavior, 1, 154-169.

[18] Gerovasiliou, S. (2009). The job satisfaction of Doctors and nurses in a public hospital of the National Healthcare System; The case of Hippocratic general regional hospital of Thessaloniki. Greek Open University, Unpublished postgraduate thesis.

[19] Herzberg, F. (1966). Work and the nature of man. Cleveland, OH: World Publishing Company

[20] Hirschfeld, R.R. (2000). Does Revising the Intrinsic and Extrinsic Subscales of the Minnesota Satisfaction Questionnaire Short Form Make a Difference?, Educational and Psychological Measurement, 60(2), 255-70.

[21] Hulin, E. (1991). Adaptation, persistence and commitment in organization. In M. D. Dunnette, \& L. M. Hough (Eds.), Handbook in Industrial and Organisational Psychology, 2, 445-506

[22] Hurlbert, J.S. (1991). Social networks, social circles and job satisfaction. Work and Occupations, 18, 415-430.

[23] In Greek: 
[24] Judge, T.A., Bono, J.E., Thoresen, C.J., \& Patto, G. K. (2001). The job satisfaction-job performance relationship: A qualitative and quantitative review. Psychological Bulletin, 127, 376-407.

[25] Kaplow, S.R. (1996). Dispositional antecedents of job satisfaction: an exploration of mediating processes. Dissertation Abstracts International: Section B: The Sciences and Engineering 56/11-B , 6434.

[26] Kim, S. (2002). Participative management and job satisfaction: Lessons for management leadership. Public Administration Review, 62, 231-241.

[27] Koustelios, A. (2001). Personal characteristics and job satisfaction of Greek teachers. International Journal of Educational Management, 15(7), 354-358.

[28] Lease, S.H. (1998). Annual review, 1993-1997: Work attitudes and outcomes. Journal of Vocational Behavior, $53,154-183$.

[29] Locke, E.A. (1974), The Nature and Causes of Job Satisfaction, in Marvin D. Dunnette, ed., Handbook of Industrial and Organizational Psychology, New York: Holt Rinehart, 1297-1349.

[30] Malka, A., \& Chatman, J.A. (2003). Intrinsic and extrinsic work orientations as moderators of the effect of annual income on subjective well-being: A longitudinal analysis. Personality and Social Psychology Bulletin, 29, 737746 .

[31] Martins, H. (2012). Minnesota Satisfaction Questionnaire - Psychometric properties and validation in a population of Portuguese hospital workers. FEP Working Papers, 471.

[32] Mathieu, J.E. (1991). Across Level Nonrecursive Model of the Antecedents of Organizational Commitment and Satisfaction. Journal of Applied Psychology, 76, 607-18.

[33] McClelland, D.C. (1961). The achieving society. New York: Van Nostrand.

[34] McNeese-Smith, D.K. (1996). Increasing employee productivity, job satisfaction, and organizational commitment. Hospital Health Service Administration, 41(2), 160-175.

[35] Moumtzoglou, A., Dafogianni, C., Karra, V., Michailidou, D., Lazarou, P., Bartsocas, C. (2000), Development and application of a questionnaire for assessing parent satisfaction with care. International Journal of Quality Health Care, 12(4), 31-7.

[36] Norrish, B.R, Rundall, T.G. (2001). Hospital restructuring and the work of registered nurses. Milbank Q 2001, 79, 55-79.

[37] O'Reilly, C.A., \& Caldwell, D. (1979). Informational influence as a determinant of perceived task characteristics and job satisfaction. Journal of Applied Psychology. 64, 157-165.

[38] Papanikolaou, G. K. (2007). Job satisfaction and burnout of doctors, nurses and administrative staff in the Papageorgiou general hospital of Thessaloniki. University of Patras, Unpublished postgraduate thesis.

[39] Schneider, B., \& Locke, E. A. (1971).A critique of Herzberg's classification system and a suggested revision. Organisational Behavior and Human Performance, 12, 441-458.

[40] Schriesheim, C.A., Powers, K. J., Scandura, T.A., Gardiner, C.C. and Lankau, M.J. (1993). Improving Construct Measurement in Management Research: Comments and a Quantitative Approach for Assessing the Theoretical Content Adequacy of Paper-and-Pencil Survey-Type Instruments. Journal of Management, 19(2), 385-417.

[41] Shalley, C.E., Gilson, L.L., \& Blum, T.C. (2000). Matching creativity requirements and the work environment: Effects on satisfaction and intent to turnover. Academy of Management Journal, 43, 215-224

[42] Shanafelt, T.D., Bradley, K.A., Wipf, J.E., \& Back, A L. (2002). Burnout and self-reported patient care in an internal medicine residency program. Annuals of Internal Medicine, 136, 358-367.

[43] Sourmpasi, M. (2006). Work fatigue, professional commitment, job satisfaction and quality of life of the medical and nursing staff in Lefkada General Hospital. University of Patras, Unpublished postgraduate thesis. 
[44] Spagnoli, P., Caetano, A., \& and Santos, S.C. (2012). Satisfaction with Job Aspects: Do Patterns Change over Time? Journal of Business Research, 65(5), 609-16

[45] Spector, P.E. (1997). Job satisfaction: Application, assessment, causes, and consequences. Thousand Oaks, CA.: Sage

[46] Sutherland V.J, Cooper C. (1992). Job stress, satisfaction, and mental health among general practitioners before and after introduction of new contract .BMJ, 304, 1545-1548.

[47] Taylor, F.W. (1911). The principles of scientific management. Harper \& Brothers, New York.

[48] Theodossiou, I., \& Pouliakas, K. (2005). Socio-economic differences in the job satisfaction of high-paid workers in Greece. Economic Bulletin of Bank of Greece, 24, 83-115.

[49] Togia, A., Koustelios, A., \& Tsigilis, N. (2004). Job Satisfaction among Greek academic librarians. Library and Information Science Research, 26, 373-383.

[50] Tountas Y., Karnaki P., Pavi E., Souliotis K. (2005). The "unexpected" growth of the private health sector in Greece. Health Policy, 74, 167-180.

[51] Trice, H., \& Beyer, J. (1993). The Culture of Work Organization, Prentice-Hall, Englewood Cliffs, NJ.

[52] Vroom, V. H. (1964). Work and Motivation. New York: Wiley.

[53] Weiss, D.J., Dawis, R.V. England, G.W. \& Lofquist, L.H. (1967). Manual for the Minnesota Satisfaction Questionnaire. Vol. 22, Minnesota Studies in Vocational Rehabilitation, Minneapolis: University of Minnesota, Industrial Relations Center.

[54] Wise, S. (2007). Wanted: the next generation of nurse and midwifery managers. International Journal of Public Sector Management 20(6), 473-483.

[55] Wu, S., Zhu, W., Wang, Z., Wang, M., Lan, Y. (2007). Relationship between burnout and occupational stress among nurses in China. Journal of Advanced Nursing 59, 233-239. 